\title{
A community-based prediabetes knowledge assessment among Saudi adults in Al-Ahsa region, 2018
}

\author{
Essa AISaleh, ${ }^{1}$ Morad Alnaser, ${ }^{2}$ Ali Alsalman, ${ }^{2}$ Abdullah ALRamdhan, ${ }^{3}$ Husein Alsalman, ${ }^{2}$ \\ Ola Alhamrani, ${ }^{3}$ Alaa Alhamrani, ${ }^{2}$ Muntadher AlSaleh, ${ }^{2}$ Tahani AlEithan, ${ }^{2}$ Khawla AlArfaj, ${ }^{2}$ \\ Hussain Al Sunayhir, ${ }^{2}$ Mujtaba AlSaleh ${ }^{4}$
}

\author{
${ }^{1}$ Postgraduate Centre for Preventive Medicine, Al-Ahsa; ${ }^{2}$ King Fahad Hofuf Hospital (KFHH), Al-Ahsa; \\ ${ }^{3}$ Family Medicine Department, Health Directorate, Al-Ahsa; ${ }^{4}$ Medical College, King Faisal University, \\ Al-Ahsa, Saudi Arabia
}

\begin{abstract}
Background: Prediabetes has been considered to be a reversible condition; a modification of lifestyle and other intervention can be successfully applied during the prediabetes period to prevent the development of type 2 diabetes. The purpose of the present study was to assess knowledge of prediabetes and its risk factors for the community in the Al-Ahsa region.

Design and method: A cross-sectional community-based study was conducted in the Al-Ahsa region from mid-to-late December 2018. A sample size of 812 was determined using a single-proportion formula.

Results: Of the 812 respondents who gave consent to participate in the interview; the male to female ratio was $1.1: 1.13 .2 \%$ of the respondents reported that they had diabetes. Among the respondents, $87.1 \%$ had a high level of knowledge of prediabetes, while $12.9 \%$ had low-to-moderate knowledge. $84 \%$ of males 40 years of age or older, $88.7 \%$ (384) of people with university or higher education, and $95.1 \%$ (78) of people who worked as health practitioners had high knowledge of prediabetes. Overall, there was a statistically significant association between age and prediabetes knowledge $\left(\chi^{2}=5.006, p=0.025\right)$. Occupation also showed a significant statistical association with prediabetes knowledge $\left(\chi^{2}\right.$ $=9.85, \mathrm{p}=0.02$ ).

Conclusion: Knowledge is considered an important factor in the prevention of prediabetes and diabetes. People in Al-Ahsa demonstrated a high level of knowledge regarding some risk factors for prediabetes. However, there were a number of deficiencies in the knowledge of prediabetes risk factors and preventive measures as well as in general knowledge of prediabetes, which may lead to a high prevalence of prediabetes and diabetes.
\end{abstract}

\section{Introduction}

Diabetes is a major growing public health issue. ${ }^{1}$ The disease currently affects around 463 million people globally ${ }^{2,3}$ and approximately 55 million in the Middle East and North Africa (MENA). ${ }^{2}$ The World Health Organization (WHO) has predicted the global prevalence of diabetes to double by $2030,3,4$ and the number of cases in MENA to rise to 108 million by $2045 .^{2}$ Furthermore, $70 \%$ of all current diabetes cases affect people in developing countries. ${ }^{5,6}$ In terms of its rate of diabetes, Saudi Arabia has been ranked by the WHO as the second highest country in the Middle East and the seventh worldwide. ${ }^{7}$ Moreover, the WHO has reported the prevalence of diabetes in Saudi adults to be as high as $18.3 \% .^{2}$ A number of other studies have reported the prevalence of prediabetes in Saudi Arabia to be between $11.9 \%$ and $27.6 \%{ }^{8-10}$

Complications and mortality related to diabetes have a worldwide impact on healthcare systems, economies and societies, families and individuals. ${ }^{11}$ Globally, the number of diabetes-related deaths in 2011 was approximately 4.6 million. ${ }^{11}$ A recent study from Saudi Arabia also showed that 25 billion Riyals is spent on healthcare for those with diabetes, while 17 billion Riyals covers the healthcare costs of all other Saudis. ${ }^{12}$ Overall, approximately $13.9 \%$ of the total healthcare expenditure in Saudi Arabia is spent on diabetes. ${ }^{12}$

Prediabetes is a condition in which blood glucose or hemoglobin A1c levels are higher than normal but not sufficiently high to be categorized as diabetes. ${ }^{13}$ According to the American Diabetes Association (ADA), people without diabetes are classified as having prediabetes if they have a glycated hemoglobin (HbA1c) value between $5.7 \%$ and $6.4 \%$, impaired fasting glucose (IFG) between 100 and $125 \mathrm{mg} / \mathrm{dl}$, or impaired glucose tolerance (IGT) between 140 and $199 \mathrm{mg} / \mathrm{dl} .{ }^{14,15}$ However, only a minority of people with prediabetes are aware of their conditions. For example, one study indicates that only $7 \%$ of the United States population with prediabetes is aware of having this condition. ${ }^{16}$

Prediabetes is a risk factor for cardiovascular disease, and individuals with prediabetes are more prone to develop type 2 diabetes than those with normal blood glucose levels. ${ }^{17}$ Recently, pre-

Significance for public health

Assessment of the community knowledge about prediabetes will have a significant impact on the control and prevention of type 2 diabetes in Saudi Arabia and worldwide, especially that Saudi Arabia is one of countries that have high prevalence of diabetes. Modification of lifestyle and other interventions can be applied during the prediabetes period to prevent the development of type 2 diabetes. Moreover, prediabetes knowledge assessment of public is unique and no research has been done about this topic in Saudi Arabia. A comprehensive evaluation of the prediabetes knowledge is required to assess its impacts on the prevention of both prediabetes and diabetes among Saudi communities. Therefore a well designed prediabetes community educational program must be constantly implemented in order to improve the diabetes awareness that lead to diabetes prevention. 
diabetes has been considered to be a reversible condition; ${ }^{18}$ a modification of lifestyle and other intervention can be successfully applied during the prediabetes period to prevent the development of type 2 diabetes. ${ }^{3}$ To the best of our knowledge there has been little or no attention paid to assessing knowledge of prediabetes and its risk factors for the community in the Al-Ahsa region of Saudi Arabia, or in Saudi Arabia more generally. Instead, previous studies have been limited to assessing the prevalence of prediabetes and its risk factors. ${ }^{8-10}$ Therefore, it is important to undertake a reliable assessment of community knowledge of prediabetes and its predictors in the Al-Ahsa region as well as in other regions in Saudi Arabia. It was also determined that there is a necessity to obtain data that assists in combating issues related to development of type 2 diabetes. To combat these issues would require designing appropriate preventive programs and policies that assist in prediabetes treatment and diabetes prevention.

\section{Design and methods}

\section{Study design and population}

A cross-sectional community-based study was conducted in the Al-Ahsa region from mid-to-late December 2018. The Al-Ahsa region is located in Saudi Arabia's Eastern Province, $160 \mathrm{~km}$ from the Arabian Gulf. It has been divided into cities and villages with various markets and shopping centers. In this study, the entire populations of Al-Ahsa were considered as the target population. Therefore, the study included all people who visited shopping centers during the study period, so long as they were over the age of 15 years and gave consent to participate in the study. These included both men and women and both those with and without diabetes. People who were younger than 15 years or who did not give consent were excluded from the study. Impaired fasting glucose or prediabetes was defined as having a fasting plasma glucose (FPG) level between $100-126 \mathrm{mg} / \mathrm{dl} .^{17,19,20}$

\section{Sampling}

A sample size of 812 was determined using a single-proportion formula based on the assumption that $50 \%$ of the study population lacked knowledge of prediabetes. There was a 95\% confidence interval, a3.44\% marginal error, and the target population was $1,063,112 .{ }^{21}$ All shopping centers, malls, and Toy Towns in the AlAhsa region were included in the community prediabetes and diabetes education program (41 centers). As a part of the education program, an assessment of prediabetes knowledge was carried out. Based on the calculated sample size, a systematic random sampling technique was used to gather the participants. To this end, every $10^{\text {th }}$ respondent of all those who came to the centers or malls during the study period from mid-to-late December 2018, fulfilled the inclusion criteria, and agreed to participate in the study was included. The first respondent was thus the $10^{\text {th }}$ respondent who agreed to participate in the study.

\section{Data collection}

The data was collected through structured face-to-face interviews with the respondents. This method was chosen over a selfadministered survey to ensure the validity of the answers. A prepiloted survey in the Arabic language was used in one of the shopping centers that were not included in the study. The data collectors asked all questions directly in a standardized manner to ensure reliability. The survey included demographic characteristics (i.e., age, sex, nationality, educational level, and occupation) and open-ended questions about prediabetes risk factors (i.e., weight, nationality, and smoking status) as well as prevention (i.e., exercise and dieting). In addition, the survey included general questions about prediabetes (i.e., "have you heard of prediabetes?" and "do you know what the normal level of HbA1c is?"). Trained interviewers conducted the interviews. Male interviewers interviewed the male participants, and female interviewers interviewed the female participants.

\section{Data analysis}

Data were entered, cleaned, checked, and analyzed using version 21 of the Statistical Package for the Social Sciences (SPSS) program. Frequency distributions were obtained, and cross-tabulation was performed to determine the correlations between the variables. A logistic regression analysis was used to identify the knowledge predictors. The chi-squared test was used to test the significance, with a p-value $<0.05$ indicating statistical significance. In addition, 95\% confidence intervals were calculated. For knowledge scoring, we used 12 questions on prediabetes. For knowledge of prediabetes risk factors and preventive measures, a score of zero was given for answering incorrectly or not knowing the answer, and a score of one for giving the correct answer. Each respondent's scores were assessed together based on Bloom's cutoff point. ${ }^{22}$ Based on the total scores, the level of knowledge was classified as high (80-100\%; respondents who had scores of 10-12 out of the 12$)$, moderate $(60 \%-80 \%$; respondents who had scores of 8-9), or low (less than 60\%; respondents who had scores of 0 7). ${ }^{23}$ The knowledge scores of the moderate and low groups were then considered together as one group with low-to-moderate knowledge.

\section{Results}

Of the 812 respondents who gave consent to participate in the interview, the male to female ratio was $1.1: 1$, such that more than half of the respondents (52\%) were male. The mean age of the respondents was 32 years, with a standard deviation of 12.3 and a range of 15-66 years. A significant proportion (51.7\%) of the respondents was older than 40 years. A minority of the respondents $(13 \%)$ had a nationality other than Saudi, whereas the majority $(87 \%)$ was Saudi nationals. More than half of respondents $(68.3 \%)$ were married (Table 1).

With regard to education level, $53 \%$ of respondents had university or higher qualifications, $27.7 \%$ had high school qualifications, and $19 \%$ had low or intermediate qualifications. With respect to occupation, $10 \%$ of the respondents were healthcare practitioners, $13.7 \%$ worked in administration, and more than half (68\%) had other occupations. The majority of the respondents $(80.8 \%)$ were non-smokers; $13.2 \%$ of the respondents reported that they had diabetes, while more than half (68\%) had a family history of diabetes (Table 1). Among the respondents, $87.1 \%$ had a high level of knowledge of prediabetes, while $12.9 \%$ had low-to-moderate knowledge. At the same time, $84 \%$ of the respondents aged 40 years or older had a high level of knowledge.

There was considerable variation in the responses among the respondents with regard to knowledge of prediabetes prevention and risk factors. Less than half $(45.6 \%)$ of the respondents had knowledge of prediabetes. However, more than half $(53.6 \%)$ of respondents knew the definition of prediabetes (either a fasting blood sugar level between 100 and $126 \mathrm{mg} / \mathrm{dl}$ or an HbA1c level 
between $5.5 \%$ and $6.4 \%$ ). The majority of respondents $(82.6 \%)$ were aware that being overweight or having an older age could cause prediabetes. Regarding prediabetes prevention, $78.2 \%$ of respondents had the knowledge that prediabetes can be prevented with regular daily exercise for at least 30 minutes or with dieting. However, less than half of the respondents $(38.7 \%)$ knew that prediabetes is symptomless; $75.7 \%$ of respondents correctly answered that people aged 45 years or older should be screened for prediabetes. At the same time, $54.7 \%$ of respondents identified that peo- ple always have prediabetes first before developing diabetes. $87.6 \%$ of respondents responded correctly that family history of type 2 diabetes is a risk factor for prediabetes. Moreover, more than two-thirds of the respondents $(73.3 \%)$ correctly identified that preeclampsia is a risk factor for prediabetes. In addition, less than half of the respondents $(46.8 \%)$ responded correctly that a body mass index equal to 20 is a risk factor for prediabetes. At the same time, $64.2 \%$ of respondents correctly identified that being Asian is a risk factor for prediabetes (Table 2).

Table 1. Characteristics of respondents in Al-Ahsa community, $2018(n=812)$.

\begin{tabular}{|c|c|c|c|}
\hline Variable & & Count & $\%$ \\
\hline Age & $\begin{array}{l}<40 \text { years } \\
\geq 40 \text { years }\end{array}$ & $\begin{array}{l}392 \\
420\end{array}$ & $\begin{array}{l}48.3 \\
51.7\end{array}$ \\
\hline Gender & $\begin{array}{l}\text { Male } \\
\text { Female }\end{array}$ & $\begin{array}{l}422 \\
390\end{array}$ & $\begin{array}{l}52.0 \\
48.0\end{array}$ \\
\hline Nationality & $\begin{array}{l}\text { Saudi } \\
\text { Non-Saudi }\end{array}$ & $\begin{array}{l}706 \\
106\end{array}$ & $\begin{array}{l}87.0 \\
13.0\end{array}$ \\
\hline Marital status & $\begin{array}{l}\text { Single } \\
\text { Married }\end{array}$ & $\begin{array}{l}257 \\
555\end{array}$ & $\begin{array}{l}31.7 \\
68.3\end{array}$ \\
\hline Education & $\begin{array}{l}\text { Intermediate school and below } \\
\text { High school } \\
\text { University and higher }\end{array}$ & $\begin{array}{l}154 \\
225 \\
433\end{array}$ & $\begin{array}{l}19.0 \\
27.7 \\
53.3\end{array}$ \\
\hline Occupation & $\begin{array}{l}\text { Health practitioner } \\
\text { Administrative } \\
\text { Business } \\
\text { Other }\end{array}$ & $\begin{array}{c}82 \\
111 \\
94 \\
525\end{array}$ & $\begin{array}{l}10.1 \\
13.7 \\
11.6 \\
64.7\end{array}$ \\
\hline History of smoking & $\begin{array}{l}\text { Yes } \\
\text { No }\end{array}$ & $\begin{array}{l}156 \\
656\end{array}$ & $\begin{array}{l}19.2 \\
80.8\end{array}$ \\
\hline Having diabetes & $\begin{array}{l}\text { Yes } \\
\text { No }\end{array}$ & $\begin{array}{l}108 \\
704\end{array}$ & $\begin{array}{l}13.2 \\
86.8\end{array}$ \\
\hline Family history of diabetes & $\begin{array}{l}\text { Yes } \\
\text { No } \\
\text { Do not know }\end{array}$ & $\begin{array}{c}552 \\
191 \\
69\end{array}$ & $\begin{array}{r}68.0 \\
23.5 \\
8.5\end{array}$ \\
\hline Knowledge & $\begin{array}{l}\text { High knowledge } \\
\text { Moderate to low knowledge }\end{array}$ & $\begin{array}{l}707 \\
105\end{array}$ & $\begin{array}{l}87.1 \\
12.9\end{array}$ \\
\hline
\end{tabular}

Table 2. Awareness of prediabetes in Al-Ahsa community, 2018 ( $n=812)$.

\begin{tabular}{|c|c|c|c|}
\hline Variable & Count & $\%$ & \\
\hline Do you know prediabetes? & $\begin{array}{l}\text { Yes } \\
\text { No }\end{array}$ & $\begin{array}{l}370 \\
442\end{array}$ & $\begin{array}{l}45.6 \\
54.4\end{array}$ \\
\hline Do you know the prediabetes definition? & $\begin{array}{l}\text { Yes } \\
\text { No }\end{array}$ & $\begin{array}{l}435 \\
377\end{array}$ & $\begin{array}{l}53.6 \\
46.4\end{array}$ \\
\hline Do you know that weight and age cause prediabetes? & $\begin{array}{l}\text { Yes } \\
\text { No }\end{array}$ & $\begin{array}{l}671 \\
141\end{array}$ & $\begin{array}{l}82.6 \\
17.4\end{array}$ \\
\hline Do you that diet and exercise for 30 min daily can treat prediabetes? & $\begin{array}{l}\text { Yes } \\
\text { No }\end{array}$ & $\begin{array}{l}635 \\
177\end{array}$ & $\begin{array}{l}78.2 \\
21.8\end{array}$ \\
\hline Do you know that prediabetes patients are symptomless? & $\begin{array}{l}\text { Yes } \\
\text { No }\end{array}$ & $\begin{array}{l}314 \\
498\end{array}$ & $\begin{array}{l}38.7 \\
61.3\end{array}$ \\
\hline Do know that 45years or old has to be screened for prediabetes? & $\begin{array}{l}\text { Yes } \\
\text { No }\end{array}$ & $\begin{array}{l}615 \\
197\end{array}$ & $\begin{array}{l}75.7 \\
24.3\end{array}$ \\
\hline Do you know that always people get prediabetes before DM? & $\begin{array}{l}\text { Yes } \\
\text { No }\end{array}$ & $\begin{array}{l}444 \\
368\end{array}$ & $\begin{array}{l}54.7 \\
45.3\end{array}$ \\
\hline Do you that family history of DM2 is a risk factor for prediabetes? & $\begin{array}{l}\text { Yes } \\
\text { No }\end{array}$ & $\begin{array}{l}711 \\
101\end{array}$ & $\begin{array}{l}87.6 \\
12.4\end{array}$ \\
\hline Do you know that pre-eclampsia is a risk factor for prediabetes? & $\begin{array}{l}\text { Yes } \\
\text { No }\end{array}$ & $\begin{array}{l}595 \\
217\end{array}$ & $\begin{array}{l}73.3 \\
26.7\end{array}$ \\
\hline Do you know that $\mathrm{BMI}=20$ is a risk factor for prediabetes? & $\begin{array}{l}\text { Yes } \\
\text { No }\end{array}$ & $\begin{array}{l}380 \\
432\end{array}$ & $\begin{array}{l}46.8 \\
53.2\end{array}$ \\
\hline Do you know that Asian is a risk factor for prediabetes? & $\begin{array}{l}\text { Yes } \\
\text { No }\end{array}$ & $\begin{array}{l}521 \\
291\end{array}$ & $\begin{array}{l}64.2 \\
35.8\end{array}$ \\
\hline
\end{tabular}


$84 \%$ of males 40 years of age or older, $88.7 \%$ (384) of people with university or higher education, and $95.1 \%$ (78) of people who worked as health practitioners had high knowledge of prediabetes. Overall, there was a statistically significant association between age and prediabetes knowledge $\left(\chi^{2}=5.006, p=0.025\right)$. In addition, there was a statistically significant association between sex and prediabetes knowledge $\left(\chi^{2}=3.89, \mathrm{p}=0.048\right)$. Occupation also showed a significant statistical association with prediabetes knowledge $\left(\chi^{2}=9.85, p=0.02\right)$. However, there was no statistically significant association between education and prediabetes knowledge $\left(\chi^{2}=2.64, \mathrm{p}=0.48\right)$ (Table 3).

The independent variables (age, sex, education, and occupation) were entered into a regression model that revealed that age had a significant statistical association with knowledge of prediabetes (Table 4).

\section{Discussion}

The present study was the first population-based study assessing prediabetes awareness in Al-Ahsa. Perception of prediabetes can lead to early detection of the condition, which is fundamental to preventing diabetes and its complications. ${ }^{24-26}$ Several studies have reported that $<10 \%$ of individuals are aware of prediabetes. ${ }^{16,27}$ In contrast to these previous studies, the present study revealed that a significantly higher percentage of respondents had a high level of knowledge of prediabetes. However, in line with previous studies, the current study highlights a range of deficiencies in knowledge about prediabetes. One previous study showed that one-third of American had prediabetes, while only $10 \%$ of these were aware of their condition. ${ }^{28}$ Another study showed that more than half of its participants were not aware of their prediabetes. ${ }^{29}$ Zhuang et al. reported a similar low percentage $(21.6 \%)$ of Chinese respondents with prediabetes who had also heard of pre- diabetes. ${ }^{30}$ However, Campbell et al. also showed that a high proportion of their total sample of 2,999 United States adults with prediabetes were aware of their status. ${ }^{31}$ The high level of prediabetes knowledge in the present study could be due to the high education level among some of the participants, which may have given them the opportunity to acquire knowledge regarding diabetes and prediabetes. Accordingly, a lack of community education programs on prediabetes could lead to deficiencies in prediabetes knowledge.

The present study also found an association between age and prediabetes awareness consistent with a previous American study that reported prediabetes awareness was lower among persons aged less than 44 years compared with those older than 44 years. ${ }^{13}$ Old age is a risk factor for prediabetes and a driver of diabetes. Therefore, raising prediabetes awareness among these age groups could help to prevent prediabetes and type 2 diabetes. ${ }^{32,33}$ One explanation for the result of the present study could be that the higher prevalence of prediabetes within older age groups that leads to greater awareness concerning the disease.

At the same time, the present study did not find any statistically significant association between education level and knowledge of prediabetes. This is in contrast to a previous study that reported significant association between education and prediabetes awareness, with the prevalence of prediabetes awareness being higher among those in the USA with greater than high school education. ${ }^{13}$ However, consisting with result of the present study, Singh and colleagues reported that regardless of educational level, none of the participants were aware of prediabetes..$^{34}$

There has also been evidence that a family history of diabetes is associated with development of the disease. ${ }^{34}$ A significant proportion of respondents in the current study with a high level of prediabetes knowledge reported that they had a family history of diabetes. This is consistent with a previous study, in which it was found that prediabetes awareness was higher among participants with a family history of diabetes than among those without. ${ }^{24}$ Campbell et al. also found that participants with prediabetes and

Table 3. Knowledge of prediabetes in relation to age, sex, education, occupation and family history among respondents ( $\mathrm{n}=\mathbf{8 1 2}$ ).

\begin{tabular}{|c|c|c|c|c|c|}
\hline & & $\begin{array}{c}\text { High knowledge } \\
\text { n (\%) }\end{array}$ & $\begin{array}{c}\text { Moderate to low knowledge } \\
\text { n (\%) }\end{array}$ & Total n (\%) & $\chi^{2}, \mathrm{p}$ \\
\hline Age & $\begin{array}{l}<40 \text { years } \\
>40 \text { years }\end{array}$ & $\begin{array}{l}352(89.8) \\
355(84.5)\end{array}$ & $\begin{array}{l}40(10.2) \\
65(15.5)\end{array}$ & $\begin{array}{l}392(100) \\
420(100)\end{array}$ & $5.006,0.025$ \\
\hline Sex & $\begin{array}{l}\text { Male } \\
\text { Female }\end{array}$ & $\begin{array}{l}358(84.8) \\
349(89.5)\end{array}$ & $\begin{array}{l}64(15.2) \\
41(10.5)\end{array}$ & $\begin{array}{l}422(100) \\
390(100)\end{array}$ & $3.89,0.048$ \\
\hline Education & $\begin{array}{l}\text { Intermediate school and below } \\
\text { High school } \\
\text { University and higher }\end{array}$ & $\begin{array}{l}129(83.8) \\
194(86.2) \\
384(88.7)\end{array}$ & $\begin{array}{l}25(16.2) \\
31(13.8) \\
49(11.3)\end{array}$ & $\begin{array}{l}154(100) \\
225(100) \\
433(100)\end{array}$ & $2.64,0.48$ \\
\hline Occupation & $\begin{array}{l}\text { Health practitioner } \\
\text { Administrative } \\
\text { Business } \\
\text { Other }\end{array}$ & $\begin{array}{c}78(95.1) \\
94(84.7) \\
75(79.8) \\
460(87.6)\end{array}$ & $\begin{array}{c}4(4.9) \\
17(15.3) \\
19(20.2) \\
65(12.4)\end{array}$ & $\begin{array}{c}82(100) \\
111(100) \\
94(100) \\
525(100)\end{array}$ & $9.85,0.02$ \\
\hline Family history of diabetes & $\begin{array}{l}\text { Yes } \\
\text { No }\end{array}$ & $\begin{array}{l}485(87.9) \\
222(85.4)\end{array}$ & $\begin{array}{l}67(12.1) \\
38(14.6)\end{array}$ & $\begin{array}{l}552(100) \\
260(100)\end{array}$ & $5.65,0.059$ \\
\hline
\end{tabular}

Table 4. Binary logistic Regression analysis showing predictors of prediabetes knowledge among respondents $(\mathrm{n}=812)$.

\begin{tabular}{lcc} 
Variables & \multicolumn{2}{c}{$\begin{array}{c}\text { Knowledge of prediabetes } \\
\text { 95\% CI }\end{array}$} \\
Age $(<40=0)^{*}$ & 0.634 & $0.415-0.97$ \\
Sex & 0.667 & $0.434-1.03$ \\
\hline Education & 0.831 & $0.639-1.08$ \\
Occupation & 1.104 & $0.089-1.37$ \\
\hline Constant & 0.357 & 0.170 \\
\hline
\end{tabular}

*Reference category; CI, confidence intervals. 
no family history of diabetes tended to be unaware of their own condition. ${ }^{31}$ Further, Li et al. also reported that prediabetes awareness was higher among participants with a family history of diabetes than among those without $(10.4 \%$ versus $6.2 \%) .{ }^{13}$ In agreement with previous studies, the participants in the current study demonstrated a high level of knowledge regarding family history of diabetes as a risk factor for prediabetes. Although it is considered impossible to improve this risk factor, a family history of diabetes leads to a high probability of increased prediabetes knowledge among the affected people. This may be due to the education given by the concerned persons to diabetes patients and/or their families. Approximately $70 \%$ of prediabetes patients develop type 2 diabetes. ${ }^{35,36}$ Further, normo-glycemic patients have an approximately $0.7 \%$ chance per year of developing type 2 diabetes, and those with impaired fasting glucose have a $5-10 \%$ chance each year. ${ }^{35}$ In the present study, a significant proportion of respondents were able to identify that people with prediabetes may develop diabetes and that prediabetes awareness may thus prevent or decrease the risk of diabetes. In line with the results of the present study, Zhuang et al. demonstrated that $28.4 \%$ of respondents were aware that prediabetes is a leading risk factor for type 2 diabetes. ${ }^{30}$

The findings of the current study also revealed that a significant proportion of respondents were aware of the risk factors of prediabetes, such as a lack of daily exercise, being overweight, and having preeclampsia. Zhuang et al. reported that less than a quarter of their Chinese participants were aware that prediabetes is a risk factor for chronic diseases, such as type 2 diabetes and cardiovascular disease. ${ }^{30}$ Several studies have attempted to assemble information concerning prediabetes knowledge in different settings with respect to risk factors and risk-reducing behaviors. ${ }^{27,31,36-38}$ Some factors noted to lower the risk of developing prediabetes were young age, non-smoking, high education level, low body mass index, and receiving advice from healthcare providers. ${ }^{30}$ In agreement with a previous study that found high levels of prediabetes knowledge regarding screening and obesity as a risk factor for prediabetes, ${ }^{39}$ the results of the present study indicate a high level of prediabetes knowledge concerning risk factors. Lorga et al. reported that their participants had low response rates to questions on exercise as a risk for prediabetes due to the fact that they did not perceive running or walking as exercise. ${ }^{3}$ Khan et al. reported similar results concerning awareness of prediabetes risk factors, finding that knowledge levels were average (53.3\%). ${ }^{38}$

However, evidence suggests that there may be gaps in knowledge about some prediabetes risk factors among various communities. For example, a study under taken by Hosler et al. demonstrated that the prevalence of self-reported prediabetes awareness was higher among older respondents ( $>45$ years), those who had family history of diabetes, and those with a body mass index $\geq 25 \mathrm{~kg} / \mathrm{m}^{2} .{ }^{40}$

The present study revealed a high level of knowledge concerning prediabetes screening in people older than 45 years even though there was no local literature addressing knowledge of prediabetes risk factors and screening. At the same time, a study under taken by Nadia et al. revealed that only a minority of participants explicitly reported that screening for prediabetes should be performed for individuals with a body mass index of $25 \mathrm{~kg} / \mathrm{m}^{2}$, and these did not mentioned age. ${ }^{39}$ Further, the same study reported that some participants had the knowledge that gestational diabetes is a risk factor for prediabetes, while more than half considered family history of diabetes a risk factor for prediabetes. ${ }^{39}$ In contrast, Khan et al. reported that a minority of respondents $(10.6 \%)$ had knowledge concerning prediabetes screening for people over 45 years old. ${ }^{38}$ In line with a previous study reporting that clinicians have greater prediabetes knowledge concerning screening and diagnosis compared with treatment, ${ }^{41}$ the current study revealed a statistically significant association between prediabetes awareness and occupation, such as for healthcare practitioners. Khan et al. also reported that medical students had poor knowledge of prediabetes prevention as well as preclinical and clinical management of the condition. ${ }^{38}$ The dissimilarities in the level of prediabetes knowledge among people of different occupations might be explained by the adequate or inadequate training received concerning prediabetes and diabetes depending on occupation. Overall, the findings of the current study are consistent with those of other studies in indicating that knowledge of prediabetes varies widely with regard to risk factors and preventive measures. Prediabetes knowledge was found to be high in some of the examined areas. However, the present study of prediabetes knowledge assessment of public is unique in Saudi Arabia and gave a model knowledge about prediabetes knowledge assessment among Saudi communities. Though, there are many areas that indicate multidisciplinary interventions to improve knowledge and lifestyle along with other risk factors would help in delaying or preventing the progression of prediabetes to diabetes. The multidisciplinary interventions would requisite a collaboration of the health authorities, policymakers, and the educational personnel to develop a welldesigned prediabetes community educational program. The designed prediabetes program must be constantly implemented in order to improve the diabetes awareness that leads to diabetes prevention.

\section{Limitations}

It must be acknowledged that there were some limitations to the present study. In particular, the data concerning prediabetes awareness was taken from in-person face-to-face interviews and might be subject to bias responses and the time-consuming nature of the interviews. Moreover, the sample may be not representative of the population, and actual levels of awareness might be higher or lower if non-participants differ from the participants. In addition, because participation was voluntary, it is possible that some level of selection bias occurred with participants who were already interested in the subject of diabetes being more likely to respond. Thus the responses may not be a true representation of the level of knowledge of prediabetes in the entire community at Al-Ahsa region. However, this was addressed by inviting all persons who fulfilled the inclusion criteria and sampling technique, and the response rate was relatively high.

\section{Implications}

A well designed prediabetes community educational program must be constantly implemented in order to improve the diabetes awareness that lead to diabetes prevention.

A comprehensive evaluation of the prediabetes knowledge is required to assess its impacts on the prevention of both prediabetes and diabetes.

Modification of lifestyle and other interventions can be applied during the prediabetes period to prevent the development of type 2 diabetes.

\section{Conclusion}

Knowledge is considered an important factor in the prevention of prediabetes and diabetes. Planned and structured educational programs have thus been recommended as an important strategy to improve compliance and reduce the risk and rates of prediabetes and diabetes. People in Al-Ahsa demonstrated a high level of knowledge regarding some risk factors for prediabetes, such as being obese, being old, and having a family history of diabetes. 
However, there were a number of deficiencies in the knowledge of prediabetes risk factors and preventive measures as well as in general knowledge of prediabetes, which may lead to a high prevalence of prediabetes and diabetes. These deficiencies reveal that there is an urgent need for mass educational programs on prediabetes to improve knowledge of the condition, and the need for prediabetes screening should also be stressed as a part of these programs. Further, investment in research investigating and assessing the prediabetes awareness and literacy of the public in the Al-Ahsa region as well as in other regions of Saudi Arabia is needed.

Correspondence: Essa AlSaleh, Consultant physician of epidemiology and public health, Postgraduate Centre for Preventive Medicine, Al-Ahsa, Directorate of Health Affairs, Al-Ahsa, Ministry of Health, Saudi Arabia.

Tel: +966.504926812 .

E- mail: emsaleh6@gmail.com

Key words: Prediabetes; knowledge; Saudi Arabia; Al-Ahsa region; community.

Contributions: All authors participated in conducting and designing the study and the manuscript writing. EA, devised the idea and study design; MA, AAS, AAR, OA, developed the data collection tool. HA, AAH, MA, TA, KA, HAS, MAS, analyzed, interpreted data and study revision. All authors have revised and approved the final version of the manuscript. All authors agreed to be accountable for all aspects of the study.

Conflict of interest: The authors declare no conflict of interest.

Funding: No funding was received in relation to the research or the preparation of the manuscript.

Acknowledgements: We would like to acknowledge Dr. Hassan AlHamrani (the owner of the inspiration of community prediabetes and diabetes education program in AlAhsa), Ahmed Al Dareese, Abass Al Salman, and Bader Al Hamad along with the diabetes team at the King Fahad Hofuf Hospital for their help in data collection.

Ethics approval and consent to participate: The study was approved by the Ethical Committee of the King Fahad Hofuf Hospital (KFHH) and by the administration of the KFHH. Verbal consent was acquired from the participants before the interviews were conducted. In addition, agreement to participate in the interview was considered as consent. The objectives, potential benefits, and anonymity of the data collection were explained to the participants before the interview. Participation in the study was voluntary, and participants could withdrawal from the interview at any point without consequence. Further, the individual benefits of participating were explained to the participants. Health education pamphlets about diabetes and prediabetes risk factors and preventive measures were given to the participants at the end of the interview.

Availability of data and materials: The data used to support the findings of the present study are available from the corresponding author upon request.

Disclaimers: The views expressed in the submitted article are authors' own work.

Received for publication: 18 November 2020.

Accepted for publication: 13 January 2021.

o Copyright: the Author(s), 2021

Licensee PAGEPress, Italy

Journal of Public Health Research 2021;10:2032

doi:10.4081/jphr.2021.2032

This work is licensed under a Creative Commons Attribution NonCommercial 4.0 License (CC BY-NC 4.0).

\section{References}

1. Al-Mutairi GF, Abdul-Halim IM, Albawi AA, El-Shazly MK. Knowledge of primary health care workers regarding $\mathrm{HbA} 1 \mathrm{c}$ as a diagnostic and monitoring test for type 2 diabetes mellitus. Greener J Med Sci 2013;3:42-52.

2. International Diabetes Federation. Middle East and North Africa. Accessed: 2020 Jun 10. Available from: https://idf.org/our-network/regions-members/middle-east-andnorth-africa/members/46-saudi-arabia.html

3. Lorga T, Aung MN, Naunboonruang P, et al. Predicting prediabetes in a rural community: A survey among the Karen ethnic community, Thasongyang, Thailand. Int $\mathrm{J}$ Gen Med 2012;5:219-25.

4. WHO. Diabetes: Fact Sheet No 312, August 2011. Accessed: 2020 Apr 21. Available from: https://www.who.int/en/newsroom/fact-sheets/detail/diabetes

5. World Diabetes Foundation. Diabetes facts 2011. Accessed: 2020 Apr 21. Available from: http://www.worlddiabetesfoundation.org/composite-35.htm

6. Islam FMA, Chakrabarti R, Islam MT, et al. Prediabetes, diagnosed and undiagnosed diabetes, their risk factors and association with knowledge of diabetes in rural Bangladesh: The Bangladesh Population-based Diabetes and Eye Study. J Diabetes 2016;8:260-8.

7. Abdulaziz Al Dawish M, Alwin Robert A, et al. Diabetes mellitus in Saudi Arabia: A review of the recent literature. Curr Diabetes Rev 2016;12:359-68.

8. Bahijri SM, Jambi HA, Al Raddadi RM, et al. The prevalence of diabetes and prediabetes in the adult population of Jeddah, Saudi Arabia - A community-based survey. PLoS One 2016;11:1-14.

9. Ghoraba M, Shiddo O, Almuslmani M, et al. Prevalence of prediabetes in Family and Community Medicine Department, Security Forces Hospital, Riyadh, Saudi Arabia. Int J Med Sci Public Health 2016;5:777.

10. Aldossari KK, Aldiab A, Al-Zahrani JM, et al. Prevalence of prediabetes, diabetes, and its associated risk factors among males in Saudi Arabia: A population-based survey. J Diabetes Res 2018;2018:2194604.

11. McAdam CM. Economic implications of type 2 diabetes management. Am J Manag Care 2013;19:S143-8.

12. Mokdad AH, Tuffaha M, Hanlon M, et al. Cost of diabetes in the Kingdom of Saudi Arabia, 2014. J Diabetes Metab 2015;6:2.

13. Li YF, Geiss LS, Burrows NR, et al. Awareness of prediabetes - United States, 2005-2010. Morb Mortal Wkly Rep 2013;62:209-12.

14. American Diabetes Association. Classification and diagnosis of diabetes. Diabetes Care 2017;40:S11-24.

15. Centers for Disease Control and Prevention (CDC). National diabetes fact sheet 2011. Atlanta: Dep Heal Hum Serv centers Dis Control Prev; 2011. Available from: https://www.cdc.gov/diabetes/pubs/pdf/methods11.pdf;

16. Geiss LS, James C, Gregg EW, et al. Diabetes risk reduction behaviors among US adults with prediabetes. Am J Prev Med 2010;38:403-9.

17. Aekplakorn W, Bunnag P, Woodward M, et al. A risk score for predicting incident diabetes in the Thai population. Diabetes Care 2006;29:1872-7.

18. Tuso P. Prediabetes and lifestyle modification: time to prevent a preventable disease. Perm J 2014; 18:88-93.

19. American Diabetes Association. Diagnosis and classification 
of diabetes mellitus. Diabetes Care 2009;32:S62-7.

20. Janiszewski PM, Janssen I, Ross R. Does waist circumference predict diabetes and cardiovascular disease beyond commonly evaluated cardiometabolic risk factors? Diabetes Care 2007;30:3105-9.

21. General Authority for Statistics [Internet]. Saudi Arabia Statistics 2017. Accessed: 2020 Jun 11. Available from: https://services.stats.gov.sa:7010/ecpbi/faces/census.jsp

22. Koo H-C, Poh BK P, Abd Talib R. Assessment of knowledge, attitude and practice towards whole grains among children aged 10 and 11 years In Kuala Lumpur, Malaysia. Int J Food Sci Nutr Diet 2015;4:171-7.

23. Yimer M. Knowledge, attitude and practices of high risk populations on louse- borne relapsing fever in Bahir Dar City, North-West Ethiopia. Sci J Public Health 2014;2:15.

24. Mainous AG, Mansoor H, Rahmanian KP, Carek PJ. Perception of risk of developing diabetes among patients with undiagnosed prediabetes: The impact of health care provider advice. Clin Diabetes 2019;37:221-6.

25. American Diabetes Association. Diagnosis and classification of diabetes mellitus. Diabetes Care 2014;37:S81-90.

26. American Diabetes Association. 10. Microvascular complications and foot care: Standards of medical care in diabetes2018. Diabetes Care 2018;41:S105-18.

27. Gopalan A, Lorincz IS, Wirtalla C, et al. Awareness of prediabetes and engagement in diabetes risk-reducing behaviors. Am J Prev Med 2015;49:512-9.

28. Centers for Disease Control and Prevention (CDC). National Diabetes Statistics Report, 2017: Estimates of diabetes and its burden in the United States. Atlanta; Centers for Disease Control and Prevention; 2017.

29. Roper KL, Thomas AR, Hieronymus L, et al. Patient and clinician perceptions of prediabetes: A mixed-methods primary care study. Diabetes Educ 2019;45:302-14.

30. Zhuang Q, Wu L, Lu Y, et al. Awareness and intervention status of prediabetes among chinese adults: Implications from a com- munity-based investigation. Int J Clin Exp Med 2015;8:44806.

31. Campbell TJ, Alberga A, Rosella LC. The impact of access to health services on prediabetes awareness: A population-based study. Prev Med 2016;93:7-13.

32. Latt TS, Zaw KK, Ko K, et al. Measurement of diabetes, prediabetes and their associated risk factors in Myanmar 2014 Diabetes Metab Syndr Obes 2019;12:291-8.

33. Kirkman MS, Briscoe VJ, Clark N, et al. Diabetes in older adults. Diabetes Care 2012;35:2650-64.

34. Post RE, Mainous AG, Gregorie SH, et al The influence of physician acknowledgment of patients' weight status on patient perceptions of overweight and obesity in the United States. Arch Intern Med 2011;171:316-21.

35. Buysschaert M, Bergman M. Definition of prediabetes. Med Clin 2011;95:289-97.

36. Kacker S, Saboo N, Sharma S, Sorout J. Quasi prospective comparative study on effect of yoga among prediabetics on progression of cardiovascular risk factors. Int $\mathrm{J}$ Yoga 2019; $12: 114$

37. Kokic V, Kokic S, Krnic M, et al. Prediabetes awareness among Southeastern European physicians. J Diabetes Investig 2018;9:544-8

38. Khan T, Wozniak GD, Kirley K. An assessment of medical students' knowledge of prediabetes and diabetes prevention. BMC Med Educ 2019;19:285.

39. Saeed N, Jaffery T, Ansari FA, et al. Knowledge and perceptions about pre-diabetes amongst doctors, medical students, and patients in a tertiary care hospital of Islamabad. J Pak Med Assoc 2019;69:527-32.

40. Hosler AS. Prevalence of self-reported prediabetes among adults participating in a community-based health awareness program, New York State. Prev Chronic Dis 2009;6:A48.

41. Keck JW, Thomas AR, Hieronymus L, Roper KL. Prediabetes knowledge, attitudes, and practices at an academic family medicine practice. J Am Board Fam Med 2019;32:505-12. 